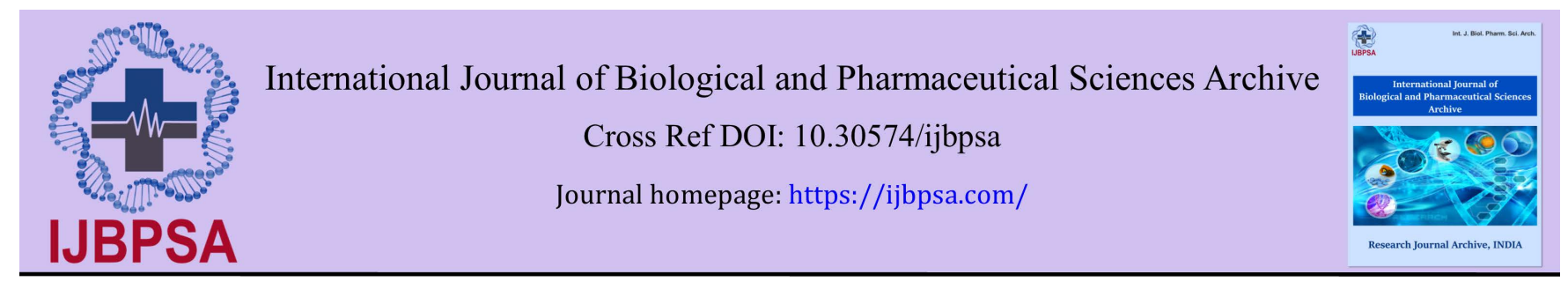

(RESEARCH ARTICLE)

\title{
Occurrence of vaginal infection (volvovaginities) among female students in Ogun State College of Health Technology, Ilese-Ijebu, Ogun State, Nigeria
}

\author{
Oladunjoye ZM* ${ }^{*}$, Quadri JA, Ojure MA and Edun BT \\ Ogun State College of Health Technology, Ilese- Ijebu, Ogun State, Nigeria.
}

International Journal of Biological and Pharmaceutical Sciences Archive, 2021, 01(02), 068-076

Publication history: Received on 29 December 2020; revised on 02 March 2021; accepted on 05 March 2021

Article DOI: https://doi.org/10.30574/ijbpsa.2021.1.2.0025

\begin{abstract}
Volvovaginitis is an inflammation of the vagina that can result in discharge, itching and pain. This study determined the occurrence of vaginal infection (volvovaginitis) among female students in Ogun State College of Health Technology, Ilese-ijebu. A validated questionnaire was used to obtain information on socio-demographic characteristics of fifty selected students and sterile swab stick was used to collect their vaginal swabs. MacConkey and Chocolate agar were used to culture the microorganisms and data were analyzed using frequency counts, percentages, correlation, and ChiSquare.
\end{abstract}

The result showed that majority of the students were in the age range of 21-25yrs and the hygienic practices of the students were poor because majority do not have access to clean water, about $45 \%$ spread their underwear in untidy environment after washing, $27 \%$ of them used any material (clothe, tissue paper, cotton wool) during their menstrual period if they could not afford sanitary pad at that moment and $15 \%$ confessed that they can wear their pants for two or three days. The isolated microorganisms showed the growth of Candida spp, Staphylococcus aureus, Klebsiella and Escherichia coli in $40 \%, 22 \%$ and $2 \%$ of the female students respectively. Chi-square showed a significant association between age and Candida spp $(\mathrm{p}=0.012)$, and Escherichia coli $(\mathrm{p}=0.004)$ while correlation shows a significant relationship between hygienic practices and identified microorganisms because unclean water was related to Klebsiella $(p=0.311)$ while dirty underwear have a significant relationship with S. aureus $(p=0.121)$.

Conclusively, this study shows the prevalence of vaginal infections amongst female students in the college and could provide important epidemiological data on vaginal infection for future population-based studies.

Keywords: Volvovaginities; Swab stick; MacConkey agar; Echerichia coli

\section{Introduction}

Vulvovaginitis is a condition in which part of the vagina becomes reddened, swollen and hot or infection of the vulva and vagina. It is a common condition that affects women and girls of all ages (4). Vaginitis is gotten when the normal amount of yeast and bacteria in the vagina gets out of balance. This could happen for several reasons, including an infection, a change in hormones, or antibiotic use. It could also be because of a reaction to something that comes into contact with the vulva or vagina. There are three common types of vaginal infections that cause vaginitis, Yeast Infection sometimes it can have too much of a fungus called Candida albicans, or candida, but an overgrowth causes yeast infections and symptoms of vaginitis, also Bacterial vaginosis a healthy vagina has lots of bacteria living in it. Some are normal flora and some are pathogenic, but they balance each other out.

${ }^{*}$ Corresponding author: Oladunjoye ZM

Ogun State College of Health Technology, Ilese- Ijebu, Ogun State, Nigeria.

Copyright $(2021$ Author(s) retain the copyright of this article. This article is published under the terms of the Creative Commons Attribution Liscense 4.0. 
The bacterial vaginosis is gotten when the bad bacteria start to outnumber the good bacteria and Trichomoniasis, this type of vaginitis comes from a tiny parasite called Trichomonas vaginalis. This is acquired through having sex with someone who is infected. Men who have this parasite do not usually have any symptoms (24). Vaginitis, which is simply the inflammation of the vaginal, is the most frequent gynecologic diagnosis encountered by physicians who provide primary care to women (5). The occurrence and causes of vaginitis are uncertain, in part, the condition is so often selfdiagnosed and self-treated. In addition, vaginitis is frequently asymptomatic (it does not show symptoms) or has more than one cause. Non-infectious causes include vaginal atrophy, allergies and chemical irritation. Most experts however, believe that up to $90 \%$ of vaginitis cases are secondary to bacterial vaginosis, vulvovaginal, candidiasis and trichomoniasis with the prevalence of bacterial vaginosis (BV) estimated to range between $9 \%$ and $50 \%$ and could be as high as 70\% in female sex workers (FSW) (13).

In the United States, bacterial vaginosis is currently the most common cause of vaginitis, accounting for $>30 \%$ of cases in women of childbearing age (21). This infection is believed to be caused by proliferation (rapid increase) of a number of organisms, including Gardnerella vaginalis, Mobiluncus species, Mycoplasma hominis and Peptostreptococcus species (12). It is believed to predispose infected women to the development of herpes simplex virus type 2 (HSV-2), Trichomonas vaginalis, Neisseria gonorrhoeae, Chlamydia trachomatis and recently HIV acquisition and transmission (6). Bacterial Vaginosis appears to be particularly common albeit with highly varied prevalence in sub-Saharan Africa with several studies reporting rates as low as $8 \%$ to a high of about $58 \%$ from different sampling conditions and regions (23).

In Ghana, it is estimated that about $25 \%$ of women are infected with BV (14). These contrast sharply with trends in industrialized countries such as North America and especially among whites, which are as low as $8.8 \%$, but could be as high as 51\% among Hispanics, blacks and aborigines (5). Europe had even much lower prevalence, 5.9\% in Ireland (23) and $13.7 \%$ in Denmark. Risk of BV has been associated with intravaginal practices most importantly douching (16). Recently however, intravaginal use of petroleum jelly has been correlated with BV especially in sex workers in Kenya (25).

The normal postmenarchal and premenopausal vaginal $\mathrm{pH}$ is 3.8-4.2. At this $\mathrm{pH}$, growth of pathogenic organisms usually is inhibited. Disturbance of the normal vaginal pH can alter the vaginal flora, leading to overgrowth of pathogens. Factors that alter the vaginal environment include feminine hygiene products, contraceptives, vaginal medications, antibiotics, sexually transmitted diseases (STDs), sexual intercourse, and stress. The overgrowth of normally present bacteria, infecting bacteria, or viruses can cause symptoms of vaginitis. Chemical irritation also can be a significant factor. Atrophic vaginitis is associated with hypoestrogenism, and symptoms include dyspareunia, dryness, pruritus, and abnormal bleeding. A state of decreased estrogen can result in an altered risk of infection. Kenyon and Colebunders found evidence that the risk of bacterial vaginosis is increased in women whose male sexual partner is concurrently having sexual relations with other partners. The age of the patient affects the anatomy and physiology of the vagina. Prepubertal children have a more alkaline vaginal $\mathrm{pH}$ than do pubertal and postpubertal adolescents and women. The vaginal mucosa is squamous epithelium, vaginal mucous glands are absent, the normal vaginal flora is similar to that of postmenopausal women (e.g., gram-positive cocci and anaerobic gram-negatives are more common), and the labia are thin with a thin hymen. Pubertal and postpubertal adolescents and women have a more acidic vaginal $\mathrm{pH}$, a stratified squamous vaginal mucosa, vaginal mucous glands, a normal vaginal flora dominated by lactobacilli, thick labia, and hypertrophied hymens and vaginal walls. Loss of vaginal lactobacilli appears to be the primary factor in the changes leading to bacterial vaginosis. Recurrences of vaginitis are associated with a failure to establish a healthy vaginal microflora dominated by lactobacilli (11).

\subsection{Objective of the study}

This study was carried out to determine the occurrence of vaginal infection (volvovaginitis) among female students in Ogun State College of Health Technology, Ilese.

\subsection{The specific objectives include}

- To assess the socio demographic and hygienic practices of the respondents

- To assess different forms of vaginal infections among female student in Ogun State College of Health Technology.

- To find out association between knowledge on practice regarding prevention of vaginal infections and selected demographic variables. 


\section{Material and methods}

\subsection{Procedure}

This study was carried out on assessment of vaginal infection (volvovaginitis) among the female students of Ogun State College of Health Technology, Ilese. Fifty samples were collected using vaginal swab. The study comprised of 50 female students aged between 16 - 35 years old. All potential eligible patients were interviewed and informed consent was obtained. Demographic data were collected and fully documented.

\subsection{Material Used}

Petri dish, Gloves, Nutrient agar, MacConkey agar, Bottle, Autoclave, Incubator, Inoculating loop or wire loop, Bunsen burner, Swab sticks, weighing balance, cotton wool, marker.

\subsection{Sample Collection}

A sterile swab stick was used to collect the vaginal swabs by a female colleague, in which she was instructed on how to collect the sample by inserting the sterile swab stick $1-2$ inches into the vaginal, twist the swab to collect material on all sides of the cotton tip, wipe in several full circles on the vaginal wall, keep in the vagina for 20 sec, and then roll each swab across a slide and allow the material to air-dry. Each sample was labeled with a serial number and kept at a temperature of $40 \mathrm{C}$ for onward transmission to the laboratory not more than $2 \mathrm{~h}$ after collection for analysis.

\subsection{Preparation of Culture Media}

Both MacConkey agar and Chocolate agar were used to culture the microorganism.

\subsection{Preparation of MacConkey agar}

$14 \mathrm{~g}$ (13.8g) of MacConkey agar was poured into $250 \mathrm{ml}$ of distilled water and allow to dissolve, the mixture was put into autoclave for sterilization for $15 \mathrm{mins}$ at $1210 \mathrm{C}$. After the sterilization the media was poured into plate and allow to gel.

\subsection{Chocolate media}

$7 \mathrm{~g}$ of nutrient agar was poured into $250 \mathrm{ml}$ of distilled water and allowed to dissolve; the mixture was put into autoclave for sterilization for $15 \mathrm{mins}$ at $1210 \mathrm{C}$. After the sterilization ten percent $(10 \%)$ of blood was poured into the $250 \mathrm{ml}$ of molten nutrient agar while hot and this later turns to chocolate media. Thereafter it was poured into the plate and allow to gel.

\subsection{Microbiological Isolate}

The samples were inoculated on both MacConkey's agar and Chocolate agar after which the Petri dishes were incubated at $37^{\circ} \mathrm{C}$ for $48 \mathrm{~h}$ in incubator.

\subsection{Biochemical Characterization and Identification of Microorganism}

The bacterial colonies were examined for appearance based on shape, elevation, edge and pigmentation. The bacterial isolates were characterized according to the methods described by Cheesbrough (2000) and MacConkey agar, Gram reaction and motility were conducted.

\subsection{Gram Reaction}

The Gram reaction was used to classify the isolates into gram positive and gram negative bacteria after examining the agar plates.

\section{Results}

This study assessed vaginal infection (volvovaginitis) among the female students of Ogun State College of Health Technology, Ilese. Fifty samples were collected using Vaginal Swab and the result obtained from the study is shown in the tables below: 
Table 1 Socio demographic and Hygienic practices of the respondents

\begin{tabular}{|c|c|c|}
\hline VARIABLE & FRE & $\%$ \\
\hline \multicolumn{3}{|l|}{ AGE } \\
\hline $15-20$ & 10 & 20 \\
\hline $21-25$ & 25 & 50 \\
\hline $26-30$ & 11 & 22 \\
\hline 30 \& Above & 4 & 8 \\
\hline Total & 50 & 100 \\
\hline \multicolumn{3}{|l|}{ Level } \\
\hline 100 & 13 & 26 \\
\hline 200 & 13 & 26 \\
\hline 300 & 12 & 24 \\
\hline 400 & 12 & 24 \\
\hline Total & 50 & 100 \\
\hline \multicolumn{3}{|c|}{ Hygienic practices (Observed by the interviewer) } \\
\hline \multicolumn{3}{|l|}{ Access to clean water } \\
\hline Yes & 18 & 36 \\
\hline No & 32 & 64 \\
\hline \multicolumn{3}{|c|}{ Place of Spreading under wears after wash } \\
\hline Clean and tidy environment & 28 & 56 \\
\hline Unclean and dirty environment & 22 & 44 \\
\hline \multicolumn{3}{|c|}{ Material used during menstruation } \\
\hline Small cloth & 6 & 12 \\
\hline Tissue paper & 4 & 8 \\
\hline Sanitary pad & 36 & 73 \\
\hline Cotton wool & 4 & 8 \\
\hline \multicolumn{3}{|l|}{ Days for putting on a pant (days) } \\
\hline 1 day & 42 & 84 \\
\hline 2-3days & 7 & 14 \\
\hline More than 3days & 1 & 2 \\
\hline Total & 50 & 100 \\
\hline
\end{tabular}


Table 2 Microscopy analysis according to age distribution

\begin{tabular}{|l|l|l|l|l|l|}
\hline Age (years) & Frequency & Pus cell & Epithelia cell & Yeast cell & RBC \\
\hline $15-20$ & 10 & 10 & 10 & 7 & 2 \\
\hline $21-25$ & 25 & 25 & 25 & 3 & 3 \\
\hline $26-30$ & 11 & 11 & 11 & 2 & - \\
\hline 31 above & 4 & 4 & 4 & - & - \\
\hline Total & $\mathbf{5 0}$ & & & & \\
\hline
\end{tabular}

Table 3 Distribution of microorganism isolated from the sample

\begin{tabular}{|l|l|l|l|l|l|}
\hline Age & No growth & Candida spp & Staph. aureus & Klebsiella & Escherichia coli \\
\hline $15-20$ & 4 & 5 & 1 & - & - \\
\hline $21-25$ & 7 & 12 & 5 & 1 & - \\
\hline $26-30$ & 5 & - & 5 & - & 1 \\
\hline 31 above & 1 & 3 & - & - & - \\
\hline Percentage & $\mathbf{3 4}$ & $\mathbf{4 0}$ & $\mathbf{2 2}$ & $\mathbf{2}$ & $\mathbf{2}$ \\
\hline
\end{tabular}

Table 4 Correlation between Age and prevalence of detected organisms

\begin{tabular}{|l|l|l|l|l|}
\hline Variable & Candida spp & Staph aureus & Klebsiella & Escherichia coli \\
\hline Age (yrs.) & & & & \\
\hline $15-20$ & 5 & 1 & - & - \\
\hline $21-25$ & 12 & 5 & 1 & - \\
\hline $26-30$ & - & 5 & - & 1 \\
\hline $31 \&$ above & 3 & - & - & - \\
\hline Spearman's rho & $0.133^{*}$ & 0.052 & 0.103 & $0.212^{*}$ \\
\hline P-value & 0.012 & 0.103 & 0.124 & 0.004 \\
\hline
\end{tabular}

Table 5 Pearson's Correlations between socio-demographic \& hygienic practices and detected organisms

\begin{tabular}{|l|l|l|l|l|}
\hline Variable & Candida spp & Staph aureus & Klebsiella & Escherichia coli \\
\hline Age & 0.096 & 0.064 & 0.060 & 0.128 \\
\hline Level & 0.059 & -0.031 & 0.060 & 0.520 \\
\hline Unclean water & $0.140^{*}$ & 0.030 & $0.311^{*}$ & 0.430 \\
\hline Untidy environment & $0.134^{* *}$ & 0.055 & 0.089 & $0.123^{*}$ \\
\hline Dirty underwear & $0.122^{*}$ & $0.121^{*}$ & -0.029 & $0.062^{*}$ \\
\hline \multicolumn{4}{|c|}{$\mathrm{p}>0.05$} \\
\hline
\end{tabular}




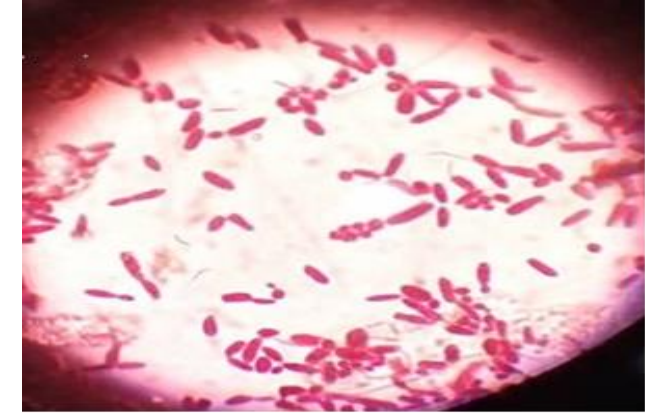

A

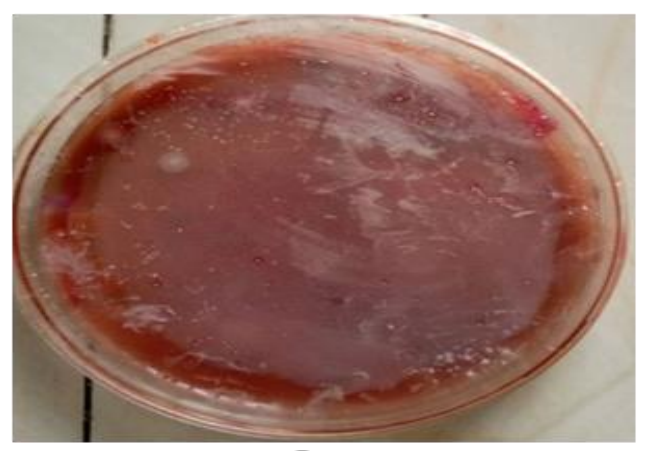

C

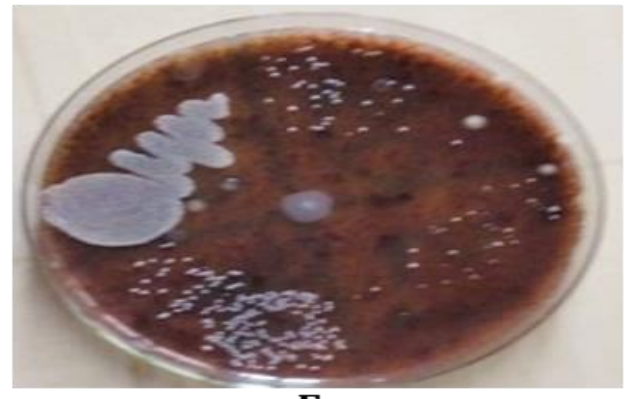

$\mathbf{E}$

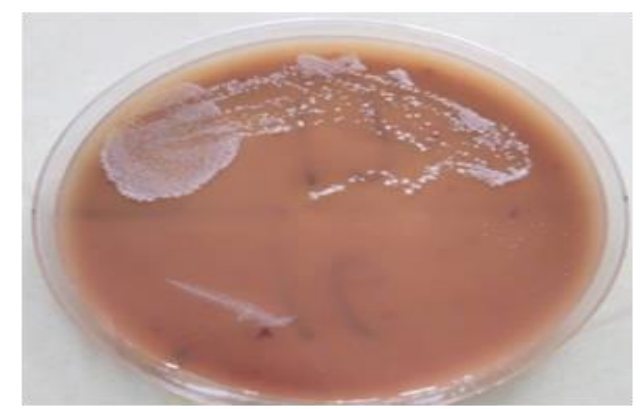

G

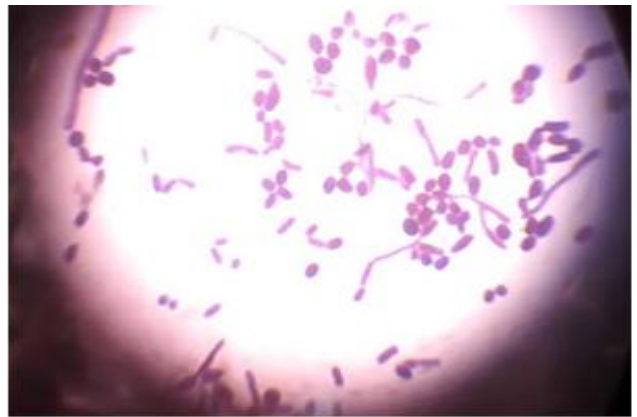

B

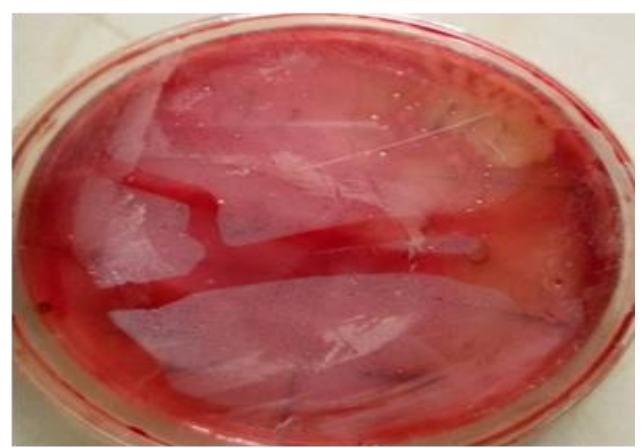

D

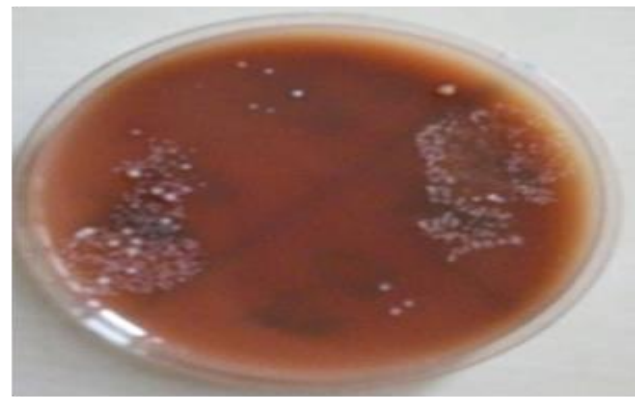

$\mathbf{F}$

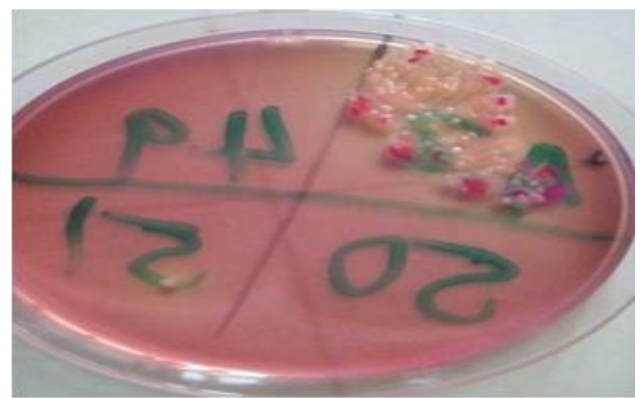

$\mathbf{H}$

Figure 1 Growth of Organisms
A - Gram Negative Bacilli (GNB)
B - Gram Positive Cocci (GPC)
C - Chocolate Medium
D - MacConkey Medium
E - Mixed growth of Staph and Candida
F - Growth of Staph only
G - Pure growth of Candida
$\mathrm{H}$ - Growth of E. coli
I - No growth
$\mathrm{J}$ - Liquid molten agar 


\section{Discussion}

Vulvovaginitis is a condition in which part of the vaginal becomes reddened and swollen. It is a common condition that affects women and girls of all ages (4). Vaginal infection is one of the most common vaginal diseases among women of reproductive age globally (2). It is caused by an imbalance in vaginal flora composition associated with behavioral factors such as vaginal douching, menstrual hygiene practices, to mention a few (17). Hormonal factors and sexual activity could also contribute to the development of volvovaginities amongst other factors.

The prevalence of vaginal infection in this study is higher than the previously reported by Muvunyi and Hernandez, (19) but extremely lower than the number reported by Lawrence et al. (26). These disparities could be due to systemic differences in the various populations as well as geographical distribution (20). The highest growth of microorganism among the females student in this study is Candida spp, followed by Staph aureus which is an opportunistic infection. This observation is consistent with the reports of Muller (18) and Emeribe et al. (7) who revealed that women in their reproductive years were more prone to vaginal candidiasis compared to other age groups. This according to them is because estrogen which induces the lining of the vagina to mature contain glycogen; a substrate on which Candida albicans thrives. Thus, the lack of estrogen production in younger and older women makes vulvo-vaginal candidiasis much less common in these age groups (9).

Those within the age group of 21-25years had the highest record of the infection while those within the age group 1520 years had a prevalence rate of $30 \%$ and this is the reverse of Maikenti et al (15) result that reported more in the age range between 15-20years. These findings revealed that the infections was almost uniformly distributed in the subjected age groups indicating that Candida spp is more frequent within the age range of 16-25 years and those within this age range were found to be sexually active. This can be attributed to several factors such as lack of personal hygiene and wearing tight under wears. This could also be due to the fact that as girls mature, hormonal changes takes place thereby making them more vulnerable to Candida albicans infection. This can also be due to the high oestrogen content of the vaginal epithelia (22).

The study also showed a relationship between the hygienic practices and development of the vaginal infection because wearing dirty under wear (pants) is significantly related to candida spp and Staph aureus while using of unclean water showed a significant relationship to candida spp and this is in line with the report of Bahram et al (3) which showed that Socio-demographic characteristics, sexual activity, reproductive health information, and behavioral and genital hygiene have been identified as causes of variation in the prevalence rates of bacterial vaginosis.

Lack of education has been found to be significantly associated with bacterial vaginosis (3). However, our finding like other studies (8) contradicted this conclusion. In the present study, bacterial vaginosis was higher among subjects having an education because the study was carried out among tertiary institution students. As far as personal hygiene is concerned, statistical analysis showed a significant correlation between frequency of vaginal infection and number of days pant can be used. Our result was in good agreement with the findings of Bahram et al. (3) who reported that bacterial vaginosis is significantly associated with individual hygiene. The result showed that even with the level of education, some of the students had different level of infection which means good hygienic practices is a way of protecting vaginal infection.

\section{Conclusion}

Conclusively, this study shows that the prevalence of vaginal infections amongst female students of the Ogun state college of health technology was relatively high and was affected by individual hygiene. Therefore, comprehensive healthcare education aimed at reducing vaginal infection is needed.

\section{Recommendations}

It is therefore recommended that:

- $\quad$ Students should be health educated.

- $\quad$ The students should be encouraged to do regular checkup probably once in six months. 


\section{Compliance with ethical standards}

\section{Acknowledgments}

The authors would like to thank the management of Ogun State college of Health Technology for releasing the laboratory for us to carry out some of the analysis and we want to specially appreciate all the students that were used as a subject in getting the samples for the study and not to forget every individual that assisted one way or the other. We are grateful.

\section{Disclosure of conflict of interest}

The author(s) declared no potential conflicts of interest with respect to the research, authorship, and/or publication of this article.

\section{References}

[1] Aubyn GB, Tagoe D. Prevalence of vaginal infections and associated lifestyles of students in the University of Cape Coast, Ghana. Asian Pacific Journal of Tropical Disease. 2013; 3(4): 267-270.

[2] Awoniyi AO, Komolafe OI, Bifarin O, Olaniran O. Bacterial vaginosis among pregnant women attending a primary health care center in Ile-Ife, Nigeria. Global Advanced ResearchJournal of Medicine and Medical Science. 2015; 4(1):057-060.

[3] Bahram A, Hamid B, Zohre T. Prevalence of bacterial vaginosis and impact of genital hygiene practices in nonpregnant women in Zanjan, Iran, Oman Medical Journal. 2009; 24(4): 288-293.

[4] Blake KJ, Baral P, Voisin T. Staphylococcus aureus produces pain through pore-forming toxins and neuronal TRPV1 that is silenced by QX-314. Nat Commun. 2018; 9: 37.

[5] Carr PL, Felsenstein D, Friedman RH. Evaluation and management of vaginitis. J Gen Intern Med. 1998; 13(5):335-346.

[6] Cherpes TL, Meyn LA, Krohn MA, Lurie JG, Hillier SL. Association between acquisition of herpes simplex virus type 2 in women and bacterial vaginosis. Clin Infect Dis. 2003; 37:319-325.

[7] Emeribe AU, Nasir IA, Onyia J, Ifunanya AL. Prevalence of Vulvovaginal Research Candidiasisis among nonpregnant women attending a tertiary health care facility in Abuja, Nigeria and Reports in Tropical Medicine. $2015 ; 6: 37-42$.

[8] Fang X, Zhou Y, Yang Y. Diao Y,Li H. Prevalence and risk factors of rural trichomoniasis, bacterial vaginosis, and candidiasis for married women of child-bearing age inShandong," Japanese Journal of Infectious Diseases.2007; 60(5): 257-261.

[9] Grigoriu D, Declacretaz J, Borelli D. Medical Mycology, Hans Huber Publishers, Hassan Toronto. 1987; $234-256$.

[10] WM Lavreys L, Chochan V, Richardson BA, Mandaliya K, Ndinya- Achola JO. Associations between intravaginal practices and bacterial vaginosis in Kenya female sex workers without symptoms of vaginal infections. Sex Transm Dis. 2007; 34:384-388.

[11] Hetal BG. FACOG is a member of the following medical societies: American College of Obstetricians and Gynecologists, Society of Laparoendoscopic Surgeons. 2017.

[12] Hill GB. The microbiology of bacterial vaginosis. Am J Obstet Gynecol. 1993; 169:450-454.

[13] Klebanoff MA, Schwebke JR, Zhang J, Nansel TR, Yu KF, Andrews WW.Vulvovaginal symptoms in women with bacterial vaginosis. Obstet Gynecol. 2004;104(2):267-272.

[14] Lassey AT, Newman MJ, Opintan JA. Vaginal flora of first time urban family planning attendants in Accra, Ghana. West Africa J Med. 2005; 24:219-222.

[15] Maikenti JI, Adogo LY, Koggie AZ,Shawulu GN.The Prevalence of Vaginal Candida Colonization among Female Students in Bingham University British, Microbiology Research Journal. 2016;12(2): 1-7.

[16] Martino JL, Vermund SH. Vaginal douching: evidence for risks or benefits to women health. Epidemiology Rev. 2002; 24:109-124. 
[17] Mbim EN, Mboto CI, George UE, Umego CF, Edet UO, Orajiaka NA. Prevalence of vaginal candidiasis among female students of a hostel in the University of Calabar, Calabar.Journal of Applied Life Science International. 2017; 13(3):1-7.

[18] Muller J. Characteristics of fungus carriers as a source of infection. Zentralbl. Hyg. Umweltmed. 1993; 194:16272.

[19] Muvunyi CM, Hernandez TC. Prevalence of bacterial vaginosis in women with vaginal symptoms in south province, Rwanda. African Journal of Clinical and Experimental Microbiology. 2009; 10(3): 156-163.

[20] Pendhakar S. The prevalence and risk factors for the most frequent lower genital tract infections among adolescents and young females (Unpublished Doctorate Thesis). Doctoral school of Semmelweiss University, Budapest. 2013; 55-60.

[21] Simhan HN, Bodnar LM, Krohn MA. Parternal race and bacterial vaginosis during the first trimester of pregnancy. Am J Obstet Gynecol. 2008; 198(2):196.

[22] Sobel JD. Vaginitis. N. Engl. J. Med. 1997; 337(18):234-236.

[23] Tolosa JE, Chaithongwongwatthana S, Daly S, Maw WW, Gaitan H, Lumbiganon P. The international infections in pregnancy (IIP) study: variations in the prevalence of bacterial vaginosis and distribution of morphotypes in vaginal smears among pregnant women. Am J Obstet Gynecol. 2006; 195:1198-1204.

[24] WebMD. Women's Health. Vaginal Infections. 2013.

[25] Hassan R, Teela S, Peninah M. Sex workers in Nairobi: Services users at BHESP. LIAS working paper 2. 2018.

[26] Lawrence U, Achi OK, Obeagu E, Elemchukwu Q. Prevalence of bacterial vaginosis among female students of Michael Okpara university of Agriculture, Umudike, Abia State, Nigeria. IOSR Journal of Pharmacy and biological Sciences.2014; 9. 39-52 